\title{
OPico dos Três Irmãos, obra interrompida de Mário de Andrade pressupostos de uma edição crítica e genética
}

\author{
Marcos Antonio de Moraes $^{1}$
}

Resumo

Pretende-se, neste artigo, refletir sobre o processo de criação de $O$ Pico dos Três Irmãos, ensaio literário interrompido de Mário de Andrade (1893-1945), conservado no espólio do escritor, no Instituto de Estudos Brasileiros da Universidade de São Paulo. Propõe-se analisar o expressivo conjunto de documentos preparatórios reunidos pelo autor, recuperando os principais fundamentos analíticos e interpretativos do estudo devotado à obra dos poetas Manuel Bandeira, Carlos Drummond de Andrade e Murilo Mendes. Abordam-se questões concernentes ao trabalho de edição crítica e genética desse manuscrito² ${ }^{2}$

\section{Palavras-chave}

O Pico dos Três Irmãos, Mário de Andrade, Carlos Drummond de Andrade, Manuel Bandeira, Murilo Mendes, edição crítica e genética.

Recebido em 2 de maio de 2013

Aprovado em 24 de julho de 2013

MORAES, Marcos Antonio de. 0 Pico dos Três Irmãos, obra interrompida de Mário de Andrade: pressupostos de uma edição crítica e genética. Revista do Instituto de Estudos Brasileiros, Brasil, n.57, p. 205-230, 2013. DOI: http://dx.doi.org/10.11606/issn.2316-901X.v0i57p205-230

1 Universidade de São Paulo (USP, São Paulo, SP, Brasil).

2 Este texto configura-se versão revista de comunicação apresentada no I Congresso Internacional de Estudos Filológicos/ VI Seminário de Estudos Filológicos (Universidade Federal da Bahia, Salvador, 2012), inserida nos anais Filologia, Críticas e Processos de Criação. Org. Célia Marques Telles e Rosa Borges dos Santos. Curitiba: Appris, 2012. Agradeço a leitura crítica de Ieda Lebensztayn e de Jaime Tadeu Oliva. 


\title{
O Pico dos Três Irmãos, Mário de Andrade's Interrupted Literary Essay Presuppositions of a Critical and Genetic Edition
}

\author{
Marcos Antonio de Moraes
}

\section{Abstract}

This article aims at reflecting on the creation process of $O$ Pico dos Três Irmãos, Mário de Andrade's (1893 - 1945) interrupted literary essay, preserved in the collection of the writer, at Instituto de Estudos Brasileiros, at Universidade de São Paulo. It proposes to analyze the set of preparatory documents gathered by the author, recovering the analytical and interpretative basis in his study about Manuel Bandeira', Carlos Drummond de Andrade' and Murilo Mendes' poetry. The article discusses some issues regarding the critical and genetic edition of this manuscript.

Keywords

O Pico dos Três Irmãos, Mário de Andrade, Carlos Drummond de Andrade, Manuel Bandeira, Murilo Mendes, critical and genetic edition. 


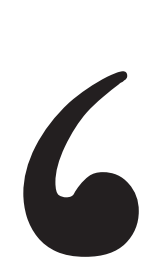

6

"guarde pra você o título provisório"

stou decidido a escrever o ano que vem um estudo sobre você", confidencia Mário de Andrade a Carlos Drummond de Andrade, em carta de 15 de outubro de 1944. No propósito de se concentrar na produção poética do amigo subsiste a admiração e o sentimento de perfeita afinidade literária ("como se fosse carne minha”) percebido, certamente, na ponte lançada entre os versos de Lira paulistana, em plena ebulição criativa, e a mais recente "poesia política” do autor de Sentimento do mundo. Pretendendo se "enterrar em poesia", Mário também conjecturava a análise de outros dois "grandes poetas", Manuel Bandeira e Murilo Mendes, considerados "tamanhos" quanto o remetente ${ }^{3}$.

Mário, em 11 de fevereiro de 1945, retoma o assunto, avaliando a possibilidade de se debruçar sobre a obra dos três poetas, conjuntamente, em um "livro", O Pico dos Três Irmãos:

[...]guarde pra você o título provisório, bom mas provisório porque não sei se ficam os três irmãos mesmo, aliás, irmãos, no caso sem decisão de maior altura só pra três (sinto que é só pra três essa altura, estes três, mas medir em crítica me parece infância) e muito menos fraternidade qualquer que não seja a límbica de Dante. Mas é que não sei também se ficam três. Dois ficam na certa: você com o Manuel. O terceiro, que seria Murilo Mendes, os compromissos já são tamanhos, tanta a trabalheira que não sei se

3 ANDRADE, Carlos Drummond de; ANDRADE, Mário de. Carlos \& Mário: correspondência completa entre Carlos Drummond de Andrade (inédita) e Mário de Andrade. Prefácio e notas de Silviano Santiago. Organização e pesquisa iconográfica de Lélia Coelho Frota. Rio de Janeiro: Bem-Te-Vi, 2002. p. 533. 
me alongo por mais esse terceiro pico. Se não me alongar, talvez conserve o título com $O$ pico dos dois irmãos. ${ }^{4}$

O título, que almeja realçar o contraste entre os poetas escolhidos e a planície comum de versejadores, empresta, possivelmente, da topografia geomorfológica mineira, o nome dos três cumes que se erguem na área metropolitana de Belo Horizonte, em Brumadinho. Essa região montanhosa abriga, no Vale do Paraopeba, a Serra do Rola Moça, assunto poético de Mário de Andrade no "Noturno de Belo Horizonte" de Clã do Jabuti (1927). A gênese da denominação do ensaio guarda certa contemporaneidade em relação à última estadia do escritor na capital de Minas Gerais, em setembro de 1944. O título do estudo talvez recupere, ainda, a reminiscência visual do Morro dos Dois Irmãos, formação majestática, no bairro do Leblon, no Rio de Janeiro, cidade na qual Mário residiu entre meados de 1938 e fevereiro de 1941. A topologia geográfica simbólica logra demarcar no movimento modernista a altitude e solidez de uma lírica que se firmava como cânone na história da literatura brasileira, abrindo-se em caminhos diversos, potencialmente frutíferos. A esse livro de interpretação literária, mobilizado por forte carga emocional ("Só ele eu amo e sinto como instância minha no momento")", se juntariam, no testemunho epistolar, outros dois projetos editoriais, $A$ Dona Ausente e Música de feitiçaria no Brasil, pesquisas no campo do folclore e da etnografia.

Revés da vida, nenhum dos três projetos, nem outros em processo, em diversos estágios de elaboração, no arquivo do escritor, chegaram a ser concluídos. Duas semanas depois daquela promissora mensagem a Drummond, Mário de Andrade sofre um enfarto fulminante. No ano anterior, em 22 de março de 1944, tendo de se submeter a uma cirurgia, ele se referira, em uma carta-testamento ao irmão Carlos, a "bastante coisa inédita, a maioria ainda se fazendo". Na ocasião, traz à baila o Sequestro da Dona Ausente e a Música de Feitiçaria no Brasil, indicando que podiam ser "publicadas tal como estão, com a advertência em subtítulo ‘conferência literária’ porque o trabalho definitivo

4. Idem, ibidem. p. 538. Em 24 de dezembro de 1944, Mário de Andrade escrevera a Guilherme Figueiredo: "Estou aprontando e dispondo as coisas pra tarefa do ano que vem. Saem dois livros, se Deus quiser, mais a Introdução pro $\mathbf{1}^{\circ}$ volume das Obras completas, mais os estudos e escritura de 'O Pico dos Três Irmãos' (livro de crítica literária de Manuel Bandeira, Carlos Drummond de Andrade e Murilo Mendes) (não conte a ninguém) que não será publicado o ano que vem ainda.” ANDRADE, Mário de. A lição do guru: Cartas a Guilherme Figueiredo (1937-1945). Rio de Janeiro: Civilização Brasileira, 1989. p. 142.

5 Idem, ibidem, p. 538. 
era muito mais sério e científico. Tal como está não passa de sugestão pra trabalhos de outrem"6. A menção à monografia Padre Jesuíno do Monte Carmelo, focalizando a vida e a obra do pintor colonial paulista, compromisso profissional de Mário com o Serviço do Patrimônio Histórico e Artístico Nacional (SPHAN), abre espaço para o depoimento sobre o próprio processo de criação, em uma das etapas redacionais da obra levada a termo em princípios de 1945:

Danças dramáticas e [...] Padre Jesuíno do Monte Carmelo [...] não só não estão em redação definitiva como contêm erros de história ou crítica, que eu pretendia corrigir depois e fui deixando assim. Muito frequente, meu processo de trabalho era assim, ir redigindo o que eu não sabia se era assim mas me palpitava ser assim, dependendo de verificação ou conhecimento futuro. Ultimamente até em dezenas de afirmativas eu continuava com um "(verificar)" por depender desse trabalho de verificação ou reverificação futura. Agia assim pra não prejudicar o ritmo normal da redação [... $]^{7}$

O testemunho da criação ganha relevo na correspondência e em outros textos memorialísticos de Mário de Andrade, contribuindo para a compreensão das principais diretrizes do ideário estético do autor. Esses depoimentos podem favorecer a apreensão do modus operandi da montagem de uma obra (procedimentos prévios, etapas), ao acusarem ações reiteradas e recursos idiossincráticos no funcionamento da engrenagem da invenção; nesse sentido, iluminam o trabalho de análise textual e genética de manuscritos inacabados ${ }^{8}$ ou interrompidos, congregados em dossiês.

Mário de Andrade, ao historiar a gestação de seus escritos, no campo da arte ou do saber, definiu métodos e singularidades redacionais,

6 Alvarenga, Oneyda. Mário de Andrade, um pouco. São Paulo: José Olympio/ SCET-CEC-SP, 1974. p. $3^{2}$.

7 Idem, ibidem, p. 32.

8 Reserva-se, aqui, o termo "inacabado" para as situações nas quais a interrupção é um gesto consciente do autor, desinteressado (ou impedido internamente) de fazer avançar um manuscrito. É o que se dá, por exemplo, em relação ao Café, romance de Mário de Andrade, estagnado após intenso trabalho de gestação e campanhas de reescritura. Mário escreve a Drummond em 24, de agosto de 1944: "Abandonei [...] não porque não viesse, mas porque eu não estava mais livre [...] desisti, em favor da minha liberdade. Da minha sinceridade [...]. (p. 526-7). Cf. FIGUEIREDO, Tatiana Longo. Café: o trajeto da criação de um romance inacabado de Mário de Andrade. 2009. 3v. Tese (Doutorado em Literatura Brasileira, Orientadora: Profa. Dra. Telê Ancona Lopez). 
fontes e intertextos, vertentes críticas e objetivos, reconhecendo os limites de compreensão do próprio artefazer. Na entrevista a Silveira Peixoto, para a Revista do Brasil, em junho de 1940, ao ser indagado sobre o "processo" que "adota para escrever", o autor de Macunaíma se vale da brincadeira ("dois mil trezentos e sessenta e cinco processos, pronto!"), arrematando categórico: “E no entanto... [...] sou metódico!”9. Em carta ao linguista Sousa da Silveira, em abril de 1935, tinha elaborado a imagem de si como intelectual interessado em muitas áreas, o qual, "falta[ndo] memória", edificava o seu conhecimento em "fichas" e "volumes" lidos. “Em mim só conservo melancolicamente como que um salão depois do baile. Pelos riscos no chão, pelas migalhas, pela desordem das cadeiras, a gente percebe que muita coisa se passou ali..."10. Recusa, nesse esboço de perfil intelectual, as brilhanturas do saber superficial, para acentuar a ideia de trabalho como forma de fundar a erudição. Mário da Silva Brito, no papel de jornalista do Diário de São Paulo, ratifica essa percepção, em 1943. Consultando "fichas" e material de pesquisa no arquivo do escritor, conclui que "se há homem organizado entre nós, intelectual que trabalha com método e leva uma vida inteiramente dedicada ao seu mister, esse é Mário de Andrade."11

As palavras "método/metódico" e "fichas" sobressaem nessas declarações. Na seara artística, quando o assunto é poesia, a exposição de princípios orientadores do labor criativo assoma em carta de Mário à escritora mineira Henriqueta Lisboa, em janeiro de 1942. O polígrafo distingue dois momentos em seu processo de criação: o primeiro, a "possessão voluntária”, perfaz a "escolha muito pensada do assunto, notas tomadas por escrito, projetos formais, um verso que surge sozinho e fixa um ritmo, pensamento constante, andar a pé sozinho principalmente de noite nos bairros longínquos, ler poesia muita, álcool sem excesso". No outro movimento, vinga a "superposição intelectual”, circunstância em que a noção de "obra-de-arte" se impõe e o artista "corri[ge], transform[a], deform[a], melhor[a], pior[a], maltrat[a], etc. etc". ${ }^{12}$ Mais do que a

9 ANDRADE, Mário de. Entrevistas e depoimentos. Org. Telê Ancona Lopez. São Paulo: T. A. Queiroz, 1983. p. 83.

10 ANDRADE, Mário de. Mário de Andrade escreve cartas a Alceu, Meyer e outros. Ed. prep. por Lygia Fernandes. Rio de Janeiro: Ed. do Autor, 1968. p. 162.

11 Id., Entrevistas e depoimentos, op. cit., p. 93.

12 ANDRADE, Mário de; LISBOA, Henriqueta. Correspondência. Org. e introdução: Eneida Maria de Souza; notas: Pe. Lauro Palú e Eneida Maria de Souza. Estabelecimento de texto: Maria Sílvia B. Ianni. São Paulo: Edusp/IEB/Peirópolis, 2o1o. p. $188-189$. 
percepção de um (ilusório) controle do ato criador, o missivista exprime a vontade de entendê-lo, reconstituindo seus trajetos.

Admitindo as vicissitudes da indagação acerca da gênese de sua obra, Mário de Andrade, em duas ocasiões, rende-se, perplexo, em face do mistério; para o jornalista Carlos Lacerda, em carta de abril de 1944, procura trilhar os meandros do "Carro da Miséria", deparando-se com o obstáculo inamovível: "Está claro que certas palavras, certos vocativos, por mais que eu me psicanalise, não consigo descobrir donde me vieram."13 Nesse mesmo ano, em duas longas cartas, em julho e agosto, dirigidas a Drummond, põe em marcha um ensaio de interpretação do poema "Num filme de B. de Mille" (o "Rei dos Reis"), de Lira paulistana. Confessa-se apaixonado "pelo fenômeno da criação estética”, afiançando não ter "como certos escritores dizem ter, pelo menos dizem, um processo único de criação artística", a não ser estar "fatalizado"; ao perscrutar as "correções, as variantes", constata que "tudo isso é duma diversidade de aspectos incontroláveis". ${ }^{14}$

Alguns dos procedimentos metodológicos que subjazem ao processo de criação de Mário de Andrade são flagrados na correspondência que trocou com seu secretário particular, José Bento Faria Ferraz, durante a temporada carioca. Em setembro de 1940, o autor de "O artista e o artesão" desejava municiar-se de elementos bibliográficos para redigir ensaio de viés sociológico sobre o preconceito de “cor” no Brasil. Estava, entretanto, longe de seu arquivo, pois na Lopes Chaves paulistana tinham ficado seu fichário, notas de pesquisa e biblioteca. Delineia, na carta, as etapas de trabalho, o trânsito entre fichas e livros, menciona a presença de "subtítulo" nas notas e de uma listagem bibliográfica, em duplicata, nas mãos deles dois, ajudando a operacionalizar a atividade:

Com o "Preto" é que a porca torce o rabo. Vão aqui os dois trabalhos que pretendo ajuntar num só e acrescentar. Leia para entender a escolha que você terá que fazer. Primeiro: tenho um livro sobre "Simbolisme des couleurs" ou coisa parecida, que foi daqui praí na última grande remessa. Me mande já. Segundo: passe este meu estudo à Gilda [Rocha], que fiquei mesmo de lhe enviar. Ela que o leia e o devolva imediatamente a você. Quanto às fichas você pelas que tiveram subtítulo, se desinteressará por todas as que

13 ANDRADE, Mário de. 71 cartas de Mário de Andrade. Coligidas e anotadas por Lygia Fernandes. Rio de Janeiro: Livraria São José, [1968]. p. 90.

14 ANDRADE, Carlos Drummond de; ANDRADE, Mário de. Carlos \& Mário. op. cit., p. $524-525$. 
tratarem de história, de escravidão, de anedotas etc. Das outras você terá pacientemente que buscar nos livros pra ver a que se referem. Só me interesso por cor preta como superstição geral europeia ou universal mesmo, provérbios, ditos e quadrinhas. Veja bem: versalhadas semicultas, eruditas ou popularesco-urbanas contra o preto, apodos em desafios, não me interessam. De poesia, só quadrinhas populares, você dando, se possível a região onde foi colhida. Além, está claro, da referência bibliográfica, pelos números (não se engane) pois tenho cópia aqui. ${ }^{15}$

No dossiê do manuscrito interrompido O Pico dos Três Irmãos, conservado no arquivo do escritor, no Instituto de Estudos Brasileiros da Universidade de São Paulo, ${ }^{16}$ composto de plano, notas de trabalho, transcrições e recortes de jornal, também se divisa um método no processo de criação, em sintonia com outras empreitadas similares do escritor. Em face dessa obra in statu nascendi, rica em vertentes interpretativas da poesia de Bandeira, Drummond e Murilo Mendes, impõe-se o desafio de edição do material, sabendo-se da inexistência de uma primeira versão, ou seja, de uma prévia elaboração textual organizadora das anotações. Diante de registros não datados, de "uma sequência não apontada", cabe, de acordo com Telê Ancona Lopez, "distinguir um encadeamento, o modo de formar plausível, uma lógica íntima capaz de vencer a desordem, atenta às barreiras temporais e à complexidade do universo da criação de um autor." 17

\section{"talvez começar com [...]"}

Sobre a mesa, o conjunto heterogêneo de documentos vinculados ao manuscrito O Pico dos Três Irmãos, matéria sem uma disposição

15 ANDRADE, Mário de; FERRAZ, José Bento Faria. Correspondência. Org. Marcos Antonio de Moraes. São Paulo: Edusp/IEB, no prelo.

16 Os documentos da Série Manuscritos de Mário de Andrade, no IEB-USP, foram indexados e classificados em dois projetos coordenados pela Profa. Dra. Telê Ancona Lopez: Mário de Andrade na pesquisa e na crítica de Literatura, Artes Plásticas e Música, através de seu Arquivo (CNPq, 1995-1998); Estudo do processo de criação de Mário de Andrade nos manuscritos de seu arquivo, em sua correspondência, em sua marginália e em suas leituras (Fapesp/IEB/FFLCH-USP, 2007-2012). No primeiro desses projetos, a bolsista CNPq Rosana Fumie Tokimatsu realizou uma primeira classificação dos documentos de O Pico dos Três Irmãos.

17 LOPEZ, Telê Ancona. "Um idílio século XX”. In: ANDRADE, Mário de. Balança, Trombeta e Battleship ou a descoberta da alma. Edição genética e crítica. São Paulo: Instituto Moreira Salles/IEB-USP, 1994. p. 68. 
lógica claramente assentada por Mário de Andrade. Dois autógrafos logo se destacam, visto que se configuram planos balizadores do assunto e dos caminhos analíticos da obra projetada. Entre eles há um nexo de contiguidade, pois o segundo escrito recupera e organiza os tópicos estabelecidos no primeiro:

\section{Pico dos 3 Irmãos}

1 - Estudar o "movimento"

2 - Estudar o "ritmo"

3 - Estudar o emprego da palavra exata

4 - Estudar o emprego da imagem

5 - Estudar o vocabulário

6 - Estudar o acomodamento da ideia (período) com a estância (estrofe)

7 - Estudar o sentido afetivo da palavra

8 - Estudar a "filosofia" de cada poeta. Mostrar a concepção crítica da vida em cada um: Deus, religião (notar aqui que nem Manuel, nem Murilo - este cristão e católico - são religiosos. Só Drummond é "religioso" no sentido de criar uma mística coletiva, embora seja dos três, o único ateu), a terra, a humanidade, a vida moral-social, o indivíduo)

9 - Estudar o sentimento (o poeta) e a expressão (a obra), seus acomodamentos, e incompetências. Manuel clássico; Drummond incapaz de qualquer classicismo preliminar: faz "clássicos" os seus poemas, pela imposição da força deles, e não pelo equilíbrio de sentimento e expressão; Murilo rejeita qualquer conceituação possível do "clássico", e terá a sua perfeição da sua própria imperfeição (Poesia em pânico), ou se abandona aos versos-ritmos fáceis (redondilhas) pra derramar dentro de uma vasilha. Mas transborda de tudo.

10 - Sentimento da natureza - Creio que em nenhum. São profundamente animistas, não se "divulgam" na natureza, como em Schmidt. Daí também não demonstrarem nenhum "prazer da vida", nenhuma alegria, a não ser Manuel, que é o mais polimorfo. Os três anti-descritivos (?). ${ }^{18}$

18 Pico dos 3 Irmãos. Autógrafo a tinta preta; 1 folha branca, amarelecida (21,9 x 16,4 $\mathrm{cm})$; sinal de dobra horizontal; escrita no anverso; sinal de ferrugem nas bordas superior e inferior: marca de clipe metálico; furos de alfinete nos quatro cantos; rasgamento na borda superior. Cumpriu-se a transcrição fidedigna deste e dos demais documentos apresentados neste artigo, atualizando-se a ortografia e respeitando- 
Forma do Livro

1 - Talvez começar com uma introdução comparativa dos três, quanto à representatividade geral do problema sentimento-expressão, poeta e poema $\left(\mathrm{O} \mathrm{n}^{\circ} 9\right.$ dos problemas a estudar, da pg. anexa)

2 - Manuel Bandeira (estudá-lo pessoalmente nos elementos 1, 2, 3, 4, 5, 6 e 7 da pg. anexa)

3 - Carlos Drummond de Andrade (idem)

4- - Murilo Mendes (idem)

5 - Estudar a mensagem dos três poetas juntos, comparativamente, com o $\mathrm{n}^{\circ} 8$ e 10 da pg.anexa.

6 - Concluir.

Nunca referir sem poema: dar logo o poema pra controle imediato do leitor. ${ }^{19}$

Aos planos, somam-se 42 notas de trabalho, algumas delas compostas por mais de um fólio; são autógrafos a tinta preta, a grafite e a lápis vermelho. As anotações, em uma visada inicial, deixam apreender três veredas, determinadas pelo próprio escritor ao encimar as fichas com o nome dos autores que pretendia estudar, ou ainda ao se referir à obra deles no corpo do escrito. Sobre a obra de Manuel Bandeira, Mário elaborou 28 notas; sobre a de Carlos Drummond de Andrade, 12; em relação à poesia de Murilo Mendes, um único apontamento. Anotação autógrafa complementar indica elementos críticos para a "comparação da prosa dos três". À parte um datiloscrito, a caligrafia ligeira, mas regular, do crítico deixa rasuras, ao cobrir a superfície dos mais diversos tipos de papel, de dimensões médias e pequenas, variadamente. Misturam-se no dossiê folhas destacadas de bloco de notas, suportes com o timbre do "BAR E RESTAURANTE 'AO FRANCISCANO" e do "MINISTÉRIO DA EDUCAÇÃO E SAÚDE” (do Instituto Nacional do Livro ou do Gabinete do Ministro), página de agenda correspondente a "SETEMBRO/ 27/ SEXTA-FEIRA", sem indicação do ano.

-se a pontuação, bem como intervenções gráficas (sublinhados) do autor; deixouse de registrar rasuras, as quais serão sinalizadas na fixação do texto, na edição em preparo. As intervenções do organizador nos textos estão indicadas com "[...]".

19 O Pico dos Três Irmãos/forma do livro. Autógrafo a tinta preta; 1 folha branca, amarelecida $(21,8 \times 16,4 \mathrm{~cm})$; sinal de dobra em 4; escrita no anverso da folha; dobras de amarfanhado; sinal de ferrugem nas bordas superior e inferior: marca de clipe metálico; furos de alfinete nos quatro cantos. 


\section{Yeco dos 3 Vreceads}

1 - Eatadar to "muserishent."

2- Frtudar o "ritivo"

3- Sntudar o enfrego da palacerse exata

4 - Entudar o supuéga da isuggen

5 - Setudar 0 soence Paris

6- Entudar a acono-daverento da c'dacia (Meriado) cone a estấecia (estrofe)

7 - Vetudar o sentedu afertiono da hataura

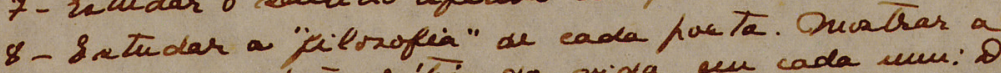

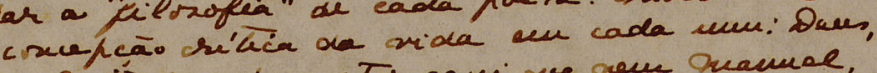

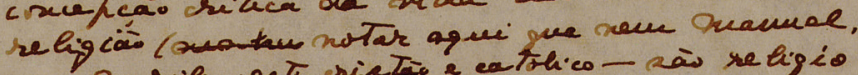

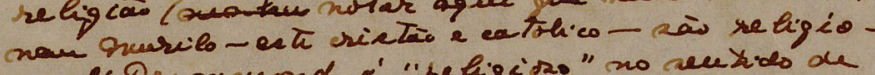

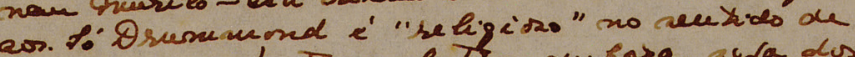

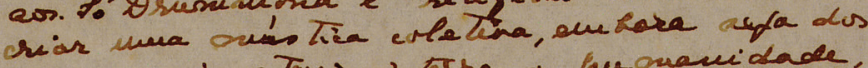

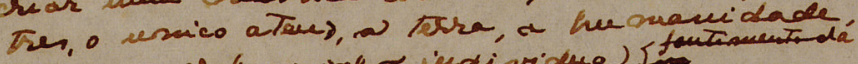

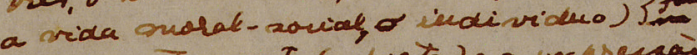

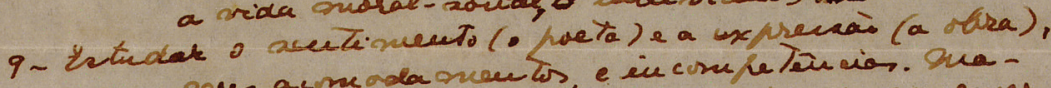

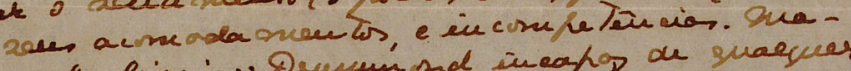

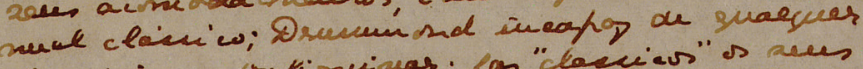

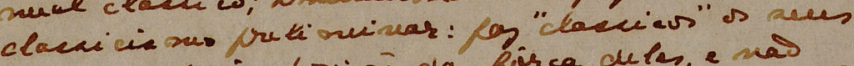

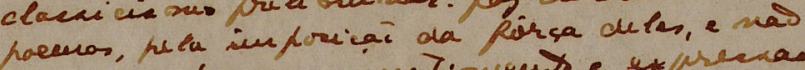

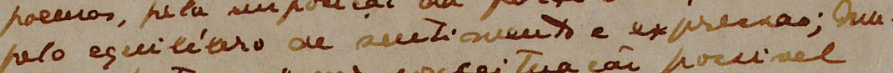

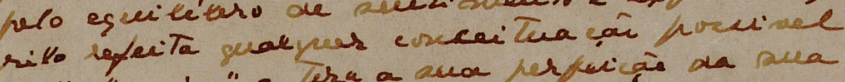

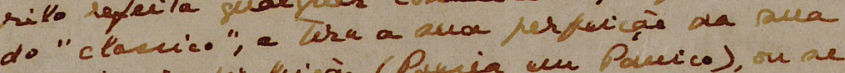

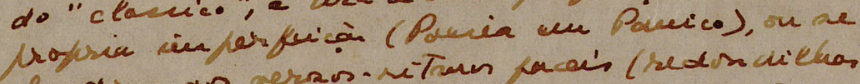

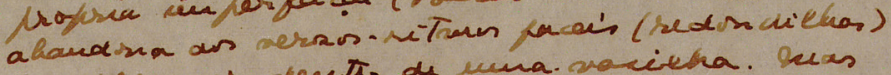

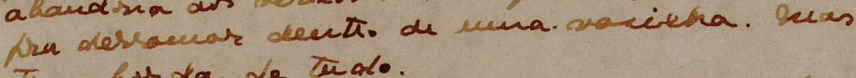
Tram bor dka de til allo.

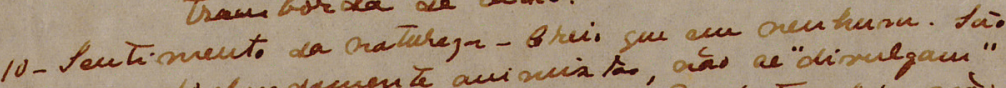

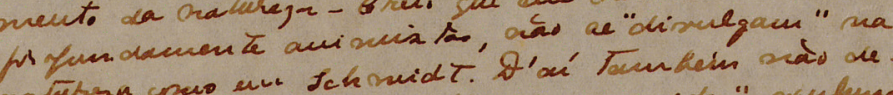

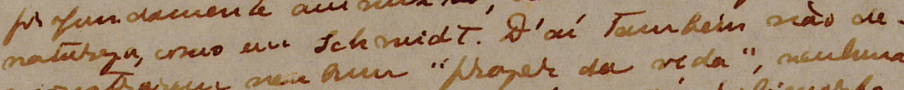

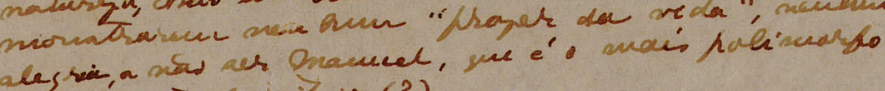
Q. Dres acuti-deritritwios (?)

Figura 1: Reprodução do autógrafo de Mário de Andrade descrito na nota 18. Arquivo IEB USP, Fundo Mário de Andrade. 


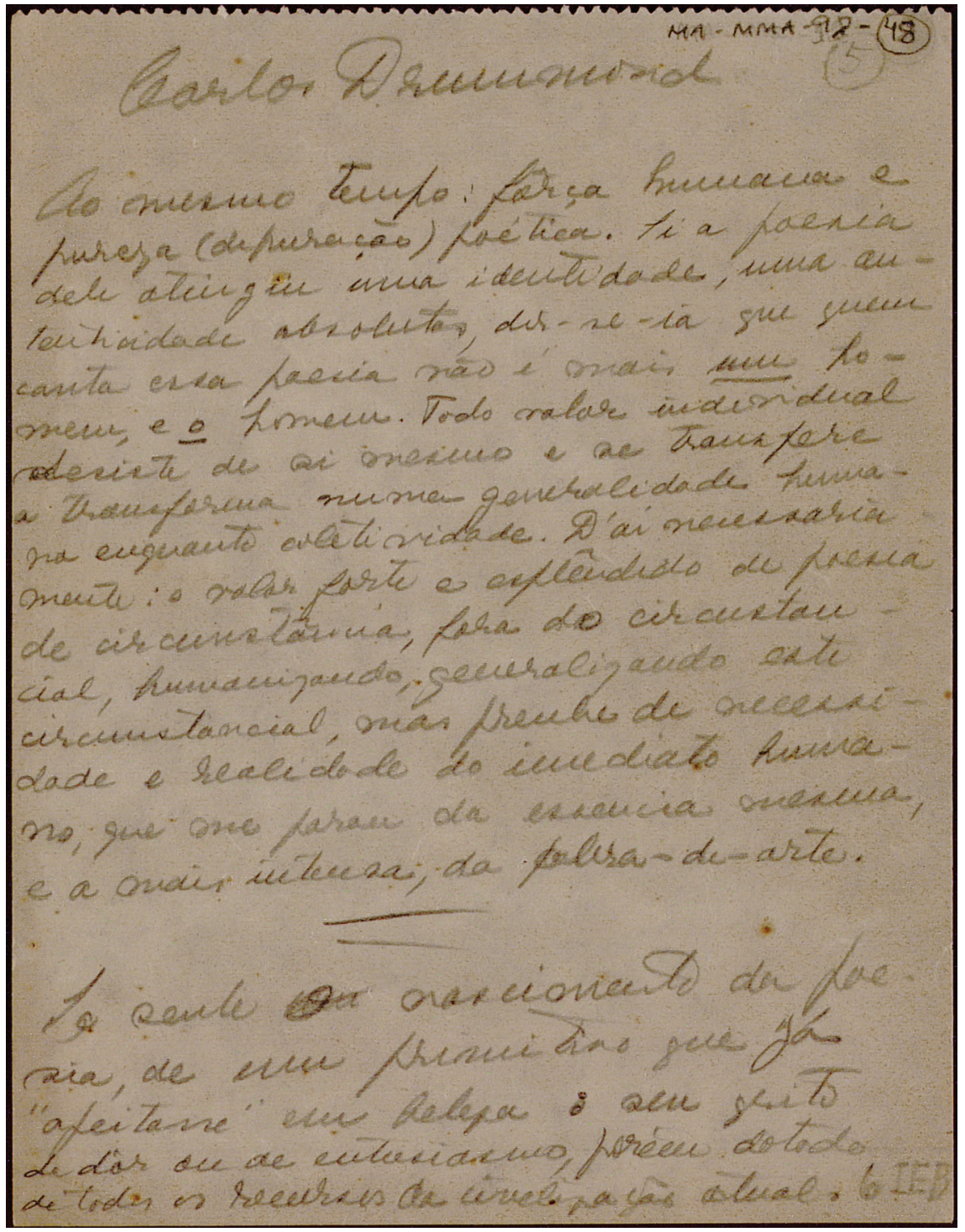

Figura 2: Nota sobre Carlos Drummond de Andrade. Arquivo IEB-USP, Fundo Mário de Andrade 


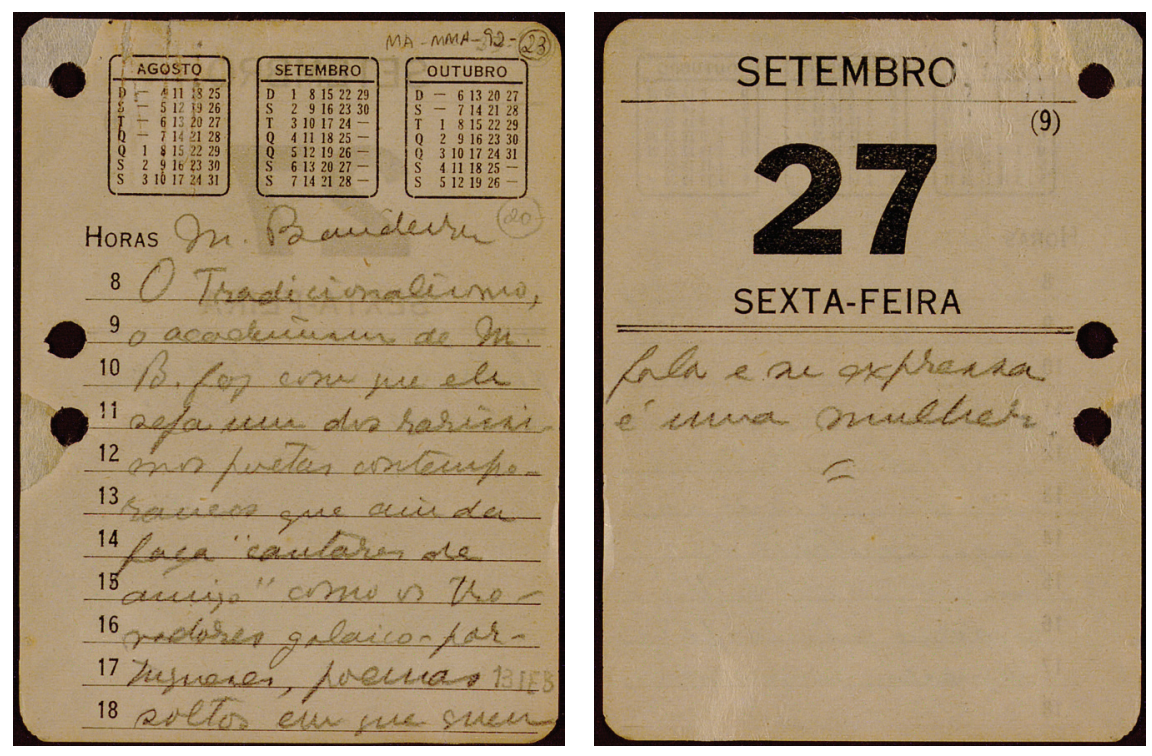

Figuras 3 e 4: Página de agenda com nota sobre Manuel Bandeira. Arquivo IEB-USP, Fundo Mário de Andrade.

Embora os textos inscritos nessas notas de trabalho não tragam datação, alguns indícios fixam possíveis marcos temporais da escrita. A folha de agenda certamente se vincula a 1940, mas, conservada talvez como papel de rascunho, pode ter sido utilizada pelo escritor em outras oportunidades; nessa nota, Mário associa o "tradicionalismo" de Bandeira ao uso que ele faz de formas poéticas do trovadorismo galaico-português. Outra anotação do crítico ilumina a intertextualidade entre o "Madrigal melancólico" de Bandeira e “Teresa" de Álvares de Azevedo, indicando uma das páginas do primeiro tomo das Obras completas do poeta romântico em sua biblioteca, edição organizada e anotada por Homero Pires, tirada do prelo da Companhia Editora Nacional em fevereiro de 1942. Os três fólios do datiloscrito congregando entradas temáticas que visam à interpretação de Sentimento do mundo de Drummond ("Dor Paroxística", "Caos lírico", "Desespero paroxístico", "Poética”, "Ritmo", "Probidade artística", "Momentos de maior humanidade" e "Causa e efeito") estão relacionados à carta de Mário ao poeta mineiro, em 15 de agosto de 1942. Nela, manifesta o propósito de estudar a obra recém-publicada do amigo:

um dia, em 1942 ou em 1952, não é promessa, é fatal, sairá o estudo. [...] Andei tomando nas leituras umas notas sobre o Sentimento do mundo. [...] o Zé Bento as copiará pra meu uso e irão os originais, 
mais difíceis de ler, mas que pelos próprios erros e letra você verá em que estado de comoção foram escritos. [...] são notas apenas sobre alguns assuntos de que pretendia falar, alguns e não todos. ${ }^{20}$

Posteriores a 2 de julho de 1943 são as duas notas que remetem ao livro Manuel Bandeira: estudo sobre a sua poesia, seguido de uma antologia, do crítico lusitano Adolfo Casais Monteiro; nessa data, segundo informa o colofão, saiu a obra das prensas da Gráfica Santelmo, em Lisboa. Outra anotação pode estar vinculada a 1944, pois menciona o artigo "Notas sobre Manuel Bandeira”, em Faces descobertas, livro do crítico literário Carlos Burlamaqui Kopke, editado nesse ano pela Livraria Martins. Ainda em alguma data ulterior a outubro de 1944, Mário redige a nota que alimenta o debate sobre a produção de Drummond,recuperando o estudo "Humor e poesia" de Álvaro Lins, presente no Jornal de crítica. 3a. Série, edição José Olympio, obra que acolheu dedicatória do autor: “A/ Mário de Andrade,/ com a estima e a admiração/ de/ Álvaro Lins/ Out. 1944”. Em duas considerações nas quais o assunto recai sobre o "sentimento trágico da [...] poesia de Drummond", o criador de Belazarte indica a origem: "Trechos de carta que escrevi ao Carlos"; "Post-scriptum da mesma carta a ele [...]". A missiva, de 15 de outubro de 1944, pode atestar o momento do registro da avaliação crítica. ${ }^{21}$

No dossiê de O Pico dos Três Irmãos, ajuntam-se aos planos e às notas de trabalho um pequeno grupo de documentos composto de recortes jornalísticos e de cópias datilografadas de poemas. Nesse repertório de textos alheios, Mário procurou dar a fonte, favorecendo a construção de uma cronologia. No que concerne a poemas de Bandeira, a transcrição datiloscrita de "Última canção do beco" não traz informações sobre a publicação; "Piscina" apresenta a data de composição ("Petrópolis, março de 1943"), mas não a de uma eventual edição; quanto a "Balada do Rei das Sereias", o recorte extraído do Correio da Manhã, do Rio de Janeiro, de 15 de outubro de 1944, fornece a ocasião de sua feitura, "Petrópolis, março de 1943". O datiloscrito do mesmo poema explicita: "Petrópolis, março 1943./ (Livros e Autores, 14-I-945)". Completam esse punhado de textos as resenhas críticas de Lauro Escorel, "As metamorfoses", com a indicação de Mário a grafite "A Manhã [Rio de Janeiro] 8-X-44" no próprio suporte do jornal, e a de Guilherme de Figueiredo, "Trajetórias”, no Diário de Notícias carioca, igualmente com o registro do escritor a grafite: " $8-\mathrm{X}-44$ ".

20 ANDRADE, Carlos Drummond de; ANDRADE, Mário de. Carlos \& Mário. op. cit., p. 479-480.

21 Idem, ibidem, p. 531-534. 
Se na carta endereçada a Carlos Drummond de Andrade, em 15 de outubro de 1944, Mário de Andrade, aparentemente, fundava o gesto inaugural do manuscrito que mais tarde receberia o título de O Pico dos Três Irmãos, a produção de alguns dos documentos a ele associados, como se viu, antecede a esse período. Em 4 de julho de 1942, ao constatar a inviabilidade de incluir nos Aspectos da literatura brasileira, em preparo, o artigo "Manuel Bandeira", veiculado em 1924 na Revista do Brasil, Mário, estimando oportuna a circunstância impeditiva, pois se desgostava da linguagem "modernista” do texto, conta ao crítico Álvaro Lins que andava "tomando umas notas pra mais um estudo sobre o Manuel"22. Assim, pode-se imaginar que, uma vez construído o percurso crítico do Pico, o autor, além das notas que passa a produzir especialmente para esse escrito, agrega matéria dispersa em seu arquivo, como, possivelmente, anotações a respeito do poeta de Libertinagem. Sob essa perspectiva, a cada novo projeto do escritor, as peças de seu arquivo da criação podiam ganhar novo estatuto, reconfigurando a distribuição dos papéis no acervo.

Talvez também seja legítimo supor que, no desenrolar do empreendimento interpretativo de largo alcance no campo dos estudos da poesia brasileira, Mário de Andrade acabaria por lançar mão do material que vinha reunindo em seu Fichário Analítico, espécie de enciclopédia pessoal dele, que tanto impressionou o jornalista Mário da Silva Brito em 1943. A cornucópia de fichas-verbetes desse manuscrito, distribuídas em dez divisões (música, literatura, artes plásticas etc.), indica trechos de livros e de periódicos na biblioteca do escritor, sugestões de abordagem crítica, citações etc., podendo armazenar com elas, matéria avulsa, como recortes jornalísticos, transcrição de cartas e outros papéis. Para recuperar apenas aquilo de que Mário poderia dispor na entrada "Manuel Bandeira", em termos de "crítica individual", contam-se trecho de carta sua ao amigo e resenhas assinadas por Tasso da Silveira, Wilson Castello Branco, Fernando Mendes de Almeida, Paulo Mendes de Almeida, José Lins do Rego, Tristão de Athayde e Otávio de Faria. Nesse conjunto documental, conserva-se ainda o esboço de análise, autógrafo a grafite, no qual o crítico versa sobre a "modéstia" de Bandeira:

Uma das principais grandezas de Manuel Bandeira, talvez a mais recôndita e a que menos tem sido salientada, é que ele é realmente tanto na vida como na obra, um poeta modesto. [...]. Ele

22 ANDRADE, Mário de. Cartas de Mário de Andrade a Alvaro Lins. Apresentação de Ivan C. Proença e comentário de José César Borba e Marco Morel. Rio de Janeiro: José Olympio, 1983. p. 67-68. 
tem a modéstia do seu cantinho e a pratica com uma sinceridade, uma discrição, uma elegância espiritual, uma segurança extraordinária. [...]. O caso do seu poema "[Evocação do] Recife" em que muitos estarão pensando naturalmente, é ainda uma prova da extrema modéstia de Manuel Bandeira. A gente poderá, não tem dúvida, lendo o título e o início do poema, imaginar que o poeta vai cantar as grandezas e belezas de sua terra natal, mas logo se desilude porém. O poeta logo converte o seu assunto ao poeta, não às características exteriores e adquiridas do poeta, não ao seu processo de versejar, ao seu estilo, a tiradas nem metáforas, mas à sua naturalidade mais intrínseca, mais incontestável, suas recordações de vida vivida, saudades de infância. Modestamente, Recife é a vida que o poeta viveu menino em um vilejo qualquer, um engenho, uma fazenda. Não é mais um assunto nacional, é um assunto do poeta vivendo no seu cantinho $[\ldots] .{ }^{23}$

No tópico "trechos” do Fichário Analítico, Mário poderia igualmente se socorrer de mais uma ficha sobre Manuel Bandeira, na qual aparecem arrolados textos do poeta em Klaxon, Estética, Revista do Brasil, Revista Nova e em outros periódicos.

Para ser exaustivo, no que tange aos veios a serem explorados em tal investida crítica, não se pode descartar o quanto o autor de Amar, verbo intransitivo se beneficiaria ao recorrer à própria marginália, em sua biblioteca, revisitando vestígios da leitura (considerações interpretativas, trechos sublinhados, sinais diversos) nas páginas dos livros da trinca de poetas que pretendia analisar.

\section{Nas raízes do Pico dos Três Irmãos}

A documentação prototextual de O Pico dos Três Irmãos parece circunscrita aos anos de 1940; as raízes desse manuscrito, entretanto, aprofundam-se na década de 1920, pois Mário de Andrade, leitor e crítico, acompanhou desde esse momento a produção de Bandeira, Drummond e Murilo Mendes, exprimindo seu parecer tanto em cartas, quanto na imprensa, ao divulgar artigos, estudos e apreciações sumárias sobre eles. Nessa direção, o dossiê que restou interrompido deve ser visto como um dos estágios do pensamento crítico em processo do autor;

23 Autógrafo a lápis, 1 folha, 32,2 x 28,o cm. Série Manuscritos Mário de Andrade: Fichário Analítico (Arquivo IEB-USP, Fundo Mário de Andrade). 
na nova etapa criativa, ele poderia trazer à memória o debate epistolar com os autores, bem como apreender, na série de críticas de sua autoria, vertentes hermenêuticas produtivas ou pouco fecundas, para avançar em reformulações e perspectivas de interpretação originais.

Em novembro de 1924, na seção "Crônicas” da Revista do Brasil, Mário focaliza as recém-publicadas Poesias de Manuel Bandeira, obra que reúne versos de Cinzas das horas (1917), Carnaval (1919) e o inédito Ritmo dissoluto. O crítico vê a tuberculose como fator determinante do fluxo lírico e do caráter contemplativo do poeta. "Esculhamba" A cinza das horas ("fraquinho") pelos assuntos poéticos batidos, pelo uso de dicção lírica alheia, proveniente da cepa simbolista e pós-simbolista, pelo humorismo convencional e por lançar mão de "exercícios de retórica". Aplaude Carnaval, porque lá encontra o poeta "prático, vivido, em função vital", não deixando, todavia, de reconhecer "que como plenitude psicológica e unidade [Carnaval] é inferior ao Ritmo dissoluto". Nos versos desse livro, detecta um "defeito saboroso", a "mania de diminuir tudo, carinhoso, por sossegado amor", supondo que o poeta não tenha reparado no procedimento recorrente. Mário flagra o escritor que "repete palavras e versos sem que ninguém se lembre de processos nem simbolismos", sublinha a opção de Bandeira pelas "coisas chués" (a "afeição pelas pequenas coisas"), tanto quanto, em Carnaval, a transcendência do individualismo, pois, para o crítico, o eu lírico ia "perdendo o seu euzinho em prol desse eu maior que é a humanidade". No último parágrafo da resenha, torna-se ostensiva a chave de leitura crítica, fundamentada, sobretudo, na observação dos vínculos entre literatura e experiência, na medida em que o autor confessa ter "busc[ado] Bandeira" nas Poesias. ${ }^{24}$

Em 1930, Mário de Andrade, cronista no Diário Nacional de São Paulo, empenha-se na divulgação de Libertinagem, de Manuel Bandeira, Alguma poesia, de Drummond, e Poemas, de Murilo Mendes, obras em circulação nesse ano. Representavam, para ele, uma "florada" 25 . Em 29 de junho, na resenha "Puro, sem mistura", o crítico coloca na ordem do dia "dois livros de admirável poesia", o de Drummond e de Bandeira. À avaliação positiva, subjaz a percepção de que "são livros dos mais puros, dos de menos concessão aos preconceitos e aos gostos alheios, que se têm publicado no Brasil. São a Poesia desembaraçada de qualquer

24. ANDRADE, Mário de. Manuel Bandeira. Revista do Brasil, 9, n. 107, Rio de Janeiro/ São Paulo, nov. 1924. p.214-224.

25 ANDRADE, Mário de. Murilo Mendes. Táxi e crônicas no Diário Nacional. Estabelecimento de texto, introdução e notas de Telê Ancona Lopez. São Paulo: Duas Cidades/Secretaria da Cultura, Ciência e Tecnologia, 1976. p. 295. 
Poética; antes Lirismo [...] lirismo intensíssimo". O crítico gosta "enormemente" dos versos, mas antevê um perigo ("beco sem saída") nessa poética "eminentemente individualista", tributária do ensimesmamento romântico, "bem longe da humanidade”. Como antídoto "mais propício a essas duas almas livres", sugere o "se evadir do indivíduo pra mais puros longes [...] o automatismo psíquico do sobre-realismo." ${ }^{26}$

A marca de transcendência da obra de arte Mário encontrará justamente nos Poemas de Murilo, livro que comentará em sua coluna, sublinhando "uma força nova em seus melhores caracteres". Na crônica "Murilo Mendes", em 21 de dezembro, o crítico alude, inicialmente, aos outros dois poetas de sua predileção e mais a Augusto Frederico Schmidt, que trouxera a lume nesse ano os versos de Pássaro cego; com Murilo, eram "o que de mais alto pode atualmente o lirismo brasileiro". Se Poemas, para o resenhista, exibia irregularidade, sobressaía-se ao refundar o poema-piada em bases mais sofisticadas e, principalmente, ao exercer o "lirismo livre, independendo da compreensão intelectual". Nos versos de cariz surrealista, o poeta "funde com o real, as coisas mais misteriosas, mais intelectualmente incompreensíveis, mais delicadamente vagas, por meio dum traço forte, bem rapaz desabusado mas família". ${ }^{27}$

Em “A poesia em 30", na seção "Crônica” do primeiro número da Revista Nova, de São Paulo, em março de 1931, Mário de Andrade se propõe a estudar "quatro livros de poetas na força do homem”, Libertinagem, Alguma poesia, Pássaro cego e Poemas. Imantava a empreitada à procura da "ordem de criação em que a poesia destes quatro grandes poetas se situa”, ou, em outras palavras, configurações da psicologia da criação. Aparecem, assim, emparelhados, pela primeira vez, os três cumes irmãos do futuro Pico. Para o crítico, Libertinagem representava a "cristalização" da psicologia de Manuel Bandeira. Se a percepção da moldagem "intratavelmente individualista" dessa lírica ratifica a avaliação exposta anteriormente em "Puro, sem mistura", agora esse traço definidor ganha nova visada interpretativa, já que poemas como "Andorinha", "O anjo da guarda", "Evocação do Recife", "Teresa” e outros teriam o condão de realizar a transposição da experiência pessoal para a coletiva: "são as poesias em que por mais pessoais que sejam assuntos e detalhes, mais o poeta se despersonaliza, mais é toda a gente e menos é

26 ANDRADE, Mário de. Puro sem mistura. Táxi e crônicas no Diário Nacional. Ed. cit, p. 213 .

27 ANDRADE, Mário de. Murilo Mendes. Táxi e crônicas no Diário Nacional. Ed. cit., p. $293^{-295}$. 
caracteristicamente ritmado". Entram em jogo, então, os vínculos entre procedimentos técnicos da poesia (verso, rítmica, metrificação) e a vitalidade humanizadora da expressão poética.

A caracterização do "individualismo também exacerbado" de Drummond conduz Mário ao exercício de prospecção de uma psicologia vincada pela timidez. Captura nos versos de Alguma poesia a tensão entre o retraimento do poeta, de um lado, e, de outro, a inteligência e sensibilidade, "coisas que se contrariam com ferocidade". Noves fora, o crítico conclui que "desse combate toda a poesia dele é feita”. Em face do entrechoque interno propulsor da criação drummondiana, logra ainda desvelar duas expressões de recalques ("sequestros") mais ou menos dissimulados nos poemas do livro: o "sexual" e o "da vida besta".

Dos quatro autores contemplados no ensaio, Poemas, de Murilo Mendes, "historicamente", podia ser visto como "o mais importante dos livros do ano". A favor dele, segundo o crítico, pesava a conquista da "essencialização poética" e a troca da "pormenorização pessoal” pela experiência "profundamente humana e genérica". O poeta nascido em Juiz de Fora tinha chegado a "um aproveitamento mais sedutor e convincente da lição sobrerrealista", quando ambiciona a "negação da inteligência superintendente, negação da inteligência seccionada em faculdades diversas, anulação de perspectivas psíquicas, intercâmbio de todos os planos [...]." 28

Nas trilhas do pensamento crítico de Mário de Andrade sobre a personalidade literária e a obra de Manuel Bandeira, depara-se, em novembro de 1936, com o texto em homenagem ao cinquentenário do escritor pernambucano, na Revista Acadêmica, do Rio de Janeiro. Nesse ano, Bandeira tinha visto seus poemas novos reunidos em Estrela da manhã, em pequena tiragem para subscritores. Na avaliação algo sibilina do crítico, a lírica bandeiriana teria atingido a essência, o "mistério", o albor do lirismo ("primeiro som inarticulado"); fisga nessa expressão poética a "cristalização" (o depuro formal), a "necessidade" (a experiência vivida) e a "condensação", este, um dos aspectos centrais apurados nas notas de O Pico dos Três Irmãos:

\section{Manuel Bandeira}

Manuel Bandeira é talvez o maior e mais importante documento brasileiro a meditar, quanto ao problema da poesia contemporânea.

28 ANDRADE, Mário de. Aspectos da literatura brasileira. 4.ed. São Paulo: Martins/ MEC, 1972. p. 27-45 
E da própria linguagem mesmo... As suas palavras e frases de poesia estabelecem as mais das vezes um tal compromisso com a prosa utilitária que, na realidade, será difícil reconhecer nelas aquele elemento paralógico pelo qual se diz agora que a poesia é o impedimento principal da linguagem perder todo contato com as forças primárias, misteriosas e mais profundas do ser.

Pra compensar, Manuel Bandeira atingiu uma tal cristalização, uma tamanha condensação e necessidade em seus poemas recentes, que qualquer frase deles, por mais clara, pode-se dizer que é completamente incompreensível.// Cada poema atual de Manuel Bandeira é um primeiro som inarticulado de recémnascido. Que pureza...

Sentimento do mundo de Drummond, impresso em 1940, obtém o julgamento de Mário de Andrade na Revista Acadêmica, edição de julho de 1941. O crítico atendia ao pedido do jovem diretor do periódico, a quem, em carta de 12 de julho de 1941, sinalizava a possibilidade de escrever "umas três linhas sobre o Drummond para a homenagem da Acadêmica” ${ }^{29}$. Na súmula crítica, Mário ressalta os liames entre a lírica do poeta mineiro e os tempos sombrios, no Brasil e no mundo:

\section{Sentimento do mundo}

Haverá, na poesia contemporânea do Brasil, uns três livros tão grandes como Sentimento do Mundo... Livros significativos talvez das contradições e indecisões da época, e por certo magnificamente expressivos dos poetas que os criaram. São todos eles admiráveis forças do homem. Sentimento do mundo é, no meio deles, a mais profunda força de humanidade. Não tenho nenhum direito de afiançá-lo maior que os outros: é o que eu prefiro.

São Paulo, 12 de julho de 1941.

Mário de Andrade ${ }^{30}$

29 Idem. Cartas a Murilo Miranda: 1934/1945. Rio de Janeiro: Nova Fronteira, 1981. p. 85 .

3o ANDRADE, Mário de. "Sentimento do Mundo". Revista Acadêmica, 56, Rio de Janeiro, jul. 1941. 


\section{"que caminha no meu assunto"}

Louis Hay, em "O manuscrito inacabado", distingue no processo escritural os vínculos entre "escrever" (práxis) e "comunicar" (extroversão). Diante do manuscrito tensionado por esses dois polos, o crítico francês se pergunta: "o que fazer dessas produções com finalidade equívoca - sem fim, às vezes - e que, no entanto, comunicam com o corpo social?"31. Nessa indagação emerge o caráter bifronte da escrita no manuscrito. O que, inicialmente, apresentava-se como pura construção mental, inapreensível, portanto, ganha materialidade, mesmo que em uma configuração linguística caótica, vacilante. Se, à primeira vista, a escritura se mostra como ato narcísico (porque serve exclusivamente ao próprio autor em seu processo de criação), por outro lado, já se configura como partilha, matéria ofertada, a despeito do autor, ao olhar do outro, contemporâneo ou futuro.

Desconsiderar a potencialidade de um manuscrito interrompido, por mais informe textualmente que se encontre, significa impedir que o texto possa "comunicar", ou seja, provocar diálogos, originar novas ideias, fazer avançar certa concepção crítica. Uma vez lançada no papel, fracionada ou em versões mais ou menos limpas de rasuras, a "obra" passa a ocupar um lugar no universo da cultura. O manuscrito de O Pico dos Três Irmãos, incipiente, espelhando, em suas notas de trabalho, as "interrupções da escrita” (fragmentos de percepções críticas), fornece, de algum modo, as "coerções unificadoras da obra" (planos e horizontes interpretativos) ${ }^{32}$.Se uma primeira versão não chegou a ser elaborada pelo autor, ela existe, em latência, sugerida pelos próprios indícios estruturantes amealhados nos documentos do dossiê. Ou ainda, o texto existe na multiplicidade de caminhos sugeridos pelo autor, todos eles orientados pelo esquema que trama a "forma do livro".

Tendo sob os olhos o manuscrito "inacabado" de Vie de Henry Brullard, de Stendhal, Gérald Rannaud formula a questão preliminar, no que toca à definição de um método editorial, em alicerces críticos consistentes: "comment éditer um tel 'ouvrage', simultanément, heureuse amphibologie! - 'oeuvre' et 'travail?" ${ }^{3} 3 \mathrm{O}$ manuscrito de O Pico dos Três Irmãos coloca em pauta discussão equivalente, já que pode

31 HAY, Louis. A literatura dos escritores: questões de crítica genética. Trad. Cleonice Paes Barreto Mourão; revisão técnica Consuelo Fortes Santiago. Belo Horizonte: Editora UFMG, 2007. p. 233.

32 Idem, ibidem, p. 227.

33 RANNAUD, Gérald. "Éditer l'inachevé, note sur une édition du manuscrit de la Vie de Henry Brulard de Stendhal”. In: DIDIER, Béatrice; NEEFS, Jacques (Dir.). Éditer 
ser visto ao mesmo tempo como "obra" (o ponto de fuga do projeto) e "trabalho" (processo, exercício de elaboração); amplia-se, contudo, o grau de complexidade de sua formalização, pois é necessário, agora, supor um (ou vários) texto(s), a partir de peças soltas, cujas conexões precisam ser aclaradas pelo pesquisador. Assumindo-se a impossibilidade de captar uma rede textual mais ou menos orgânica, cada registro (nota de trabalho) poderia ser tomado como uma "obra", em seu poder de fecundação de ideias nos estudos literários.

Preliminarmente, da análise do manuscrito enquanto "trabalho" emerge o testemunho de aspectos do método de criação do escritor. Como constatou Telê Ancona Lopez em suas pesquisas sobre os manuscritos de Mário de Andrade, no IEB-USP, o escritor, uma vez publicada a obra, descartava quase integralmente o bagaço prototextual. Assim, as pegadas de seu processo de trabalho ficaram mais visíveis apenas em obras interrompidas ou inacabadas. No dossiê do Pico, Mário lança mão de pelo menos quatro recursos de estruturação prévia da obra: as células de análise, a fonte bibliográfica, a colaboração de seus pares no empreendimento analítico e o trânsito de documentos entre os manuscritos de seu acervo.

Em maior número entre as notas preparatórias do manuscrito, os núcleos analíticos caracterizam-se por formulações mais ou menos desenvolvidas acerca de aspectos da obra poética dos autores em foco. Podem, em estilo telegráfico, fixar um modo de compreensão de valores expressos na poesia ("Manuel Bandeira/ Condensação// Irmã p. 32/ Mãe p. 33, 41, 91"), distinguindo, no caso, um tema ("condensação"), a presença dele nas imagens líricas (“irmã”, “mãe”) e as páginas do livro nas quais se localizam os versos que, para o crítico, patenteiam o procedimento lírico observado. A atividade de interpretação está balizada nas notas.

Os registros mais desenvolvidos pelo escritor constituem análises formais, temáticas e da psicologia da criação, guiadas pelos dois "planos" do manuscrito. Muitas notas de trabalho perfazem cortes transversais na obra analisada, com a finalidade de perceber, por exemplo, como uma sequência de versos de Manuel Bandeira manifesta a "ascensão gradativa do particular para o geral, do símbolo para a síntese”. As anotações consubstanciam o diálogo do autor consigo próprio, espraiando-se no currente calamo da reflexão que ganha forma, sem se descurar da linguagem ensaística.

des manuscrits: archives, complétude, lisibilité. Saint-Denis: Presses Universitaires de Vincennes, 1996. p. 142. 
Na apreciação da poesia de Murilo Mendes, embora a expressão "Elemento popular" procure circunscrever o assunto de interesse na nota, Mário atenta também para questões ligadas à fatura dos versos e ao desenho de uma cosmovisão lírica vincada pelo "misticismo":

\section{Murilo Mendes \\ Elemento popular}

Há uma curiosa base popular, como que um elemento tradicional de sangue popular alimentando a obra tão transcendente deste poeta:

1-O metro da redondilha, único metro que ele usa, além do verso livre.

2-Alusões frequentes a livros, heróis, mitos populares ou popularescos.

[...] Por mais que o poeta acalme o seu espírito em Parábola, há sempre uma visão catastrófica de castigo, um pairar de perigo terrível, uma profecia de grandes tragédias dominando a sua poesia. Já agora o misticismo de M. Mendes não se alimenta, não se entretece de pecado, não implica o viver [no] pecado como no livro anterior. A sua religião não implica direta e imediatamente mais a contribuição do pecado, mas a virtude máxima que exerce é ainda o temor de Deus. Murilo treme, estremece e se confrange em dores angustiadas ante o Deus Terrível. [...]"34

Quando, em uma das anotações de pesquisa, Mário assinala que "No livro de Casais Monteiro sobre 'Manuel Bandeira' p. 47, tem um período citável pro meu estudo. Ler também todo o último cap. IV, p. 49 e ss. que caminha no meu assunto", a formulação evidencia, em primeiro lugar, o caráter dialógico da leitura, desaguando no processo de escrita. Observa-se, ainda, de um lado, que o arcabouço da obra em processo já se encontra bem moldado na consciência criadora do autor ("caminha no meu assunto"), embora não apareça expresso no documento; de outro lado, que a voz alheia - a do crítico português - poderia ratificar os passos do juízo crítico postos à prova, ou permanecer como julgamento paralelo, abrindo-se para outras possibilidades de leitura de uma obra ou ainda para a divergência de pontos de vista. Do mesmo modo,

34. Murilo Mendes/ Elemento Popular. Autógrafo a tinta preta; I folha destacada de bloco, branca, amarelecida (22,1 x 16,0 cm); timbre: brasão da República, "MINISTÉRIO DA EDUCAÇÃO E SAÚDE/ INSTITUTO NACIONAL DO LIVRO”; sinal de dobra em 2; sinal de fungo; escrita no anverso; rasuras. 
a menção "ao período citável” do volume na biblioteca do escritor tanto pode sugerir afinidade de pensamento, quanto o contraponto de ideias que viria fortalecer uma hipótese interpretativa presente no estudo em progresso. Em outro documento no dossiê, Mário resgata a própria produção, ao recomendar "Ver também minha crítica da Revista Nova o que digo sobre Pasárgada (p. 128)".

No manuscrito de O Pico dos Três Irmãos presentificam-se fios da rede de sociabilidade intelectual de Mário de Andrade: o autor incorpora a sugestão da prima Gilda Rocha (depois, Gilda de Mello e Sousa, professora de Estética da Universidade de São Paulo), para o estudo da poesia de Carlos Drummond de Andrade. No apontamento, recupera-se o testemunho de que a jovem colaboradora tinha surpreendido a intertextualidade entre o "Poema de sete faces" do escritor itabirano e versos do poeta romântico inglês William Blake (1757-1827):

\author{
"...um anjo quando eu nasci \\ Vai, Carlos, vai ser gauche na vida”
}

Carlos Drummond

Eis o poema Injunction de William Blake

\begin{abstract}
"The angel that presided o'er my birth
Said, 'Little creature, formed of joy and mirth, Go, love without the help of anything on earth".
\end{abstract}

(Gilda Morais Rocha é que descobriu) $)^{35}$

Sendo o arquivo pessoal um conjunto de vasos comunicantes, pode-se compreender o trânsito de uma anotação inicialmente agregada a ensaio sobre autor romântico para o dossiê que evoca três bardos do século XX. Versão do texto desse manuscrito ganha, num primeiro momento, letra tipográfica na nota de rodapé “(4)" de ensaio "Castro Alves", nos Aspectos da literatura brasileira, publicação de 1943. No escrito, Mário evoca a lírica de Gonçalves Dias; afirma que, diferentemente daquela do poeta dos escravos, o autor de "Canção do exílio" soube "conservar à palavra uma fluidez originária, que torna o assunto bem maior que a inteligência consciente e que o exato sentido". Manuel

35 Carlos Drummond. Autógrafo a grafite e à tinta preta; 1 folha destacada de bloco, branca, amarelecida $(14,5 \times 10,5 \mathrm{~cm})$; rasgamento no canto superior direito; escrita no anverso. 
Bandeira será, então, lembrado, pois também ele "conserva a fluidez das palavras e nos dá por isso maior libertação da inteligência lógica."36 Transposto para o Pico, o manuscrito participa de um novo sistema produtor de significados, rearranjo que deixaria os poetas românticos em segundo plano ou completamente na sombra.

Se os documentos de processo de O Pico dos Três Irmãos facultam a percepção das linhas mestras do escrito em preparo (a "forma do livro"), assim como a compreensão de procedimentos metodológicos dos quais o autor se serviu no exercício criativo, a ambição de organizar esse manuscrito interrompido, em um todo coerente, tendo em vista a edição dele, pressupõe uma trajetória espinhosa. Considerando-se que os fragmentos podem ser tomados como uma "obra", em sua potencialidade de suscitar novos estudos sobre a poesia de Bandeira, Drummond e Murilo Mendes, a tarefa de montagem do conjunto de retalhos textuais, em termos de ordenação produtora de significados, demarcando conexões internas, só pode ser obra do organizador. Uma obra que poderá, inclusive, ampliar-se, no esforço de incorporação, ao projeto editorial, das raízes do pensamento do autor (outros textos divulgados, testemunhos em cartas, transcrição da marginália etc.) e das fontes referidas em cada nota, ou seja, da transcrição dos excertos sobre os quais o autor pretendia fundamentar suas considerações.

Em demanda de uma virtual tessitura do Pico, as notas de trabalho vinculadas à interpretação da obra de Manuel Bandeira revelam duas vertentes, designadas pelo próprio Mário de Andrade, pois nomeiam muitas das folhas: "Manuel clássico" e "Condensação"; outras sendas, contudo, se abrem para perquirições: "fontes de inspiração em M. Bandeira", o "tradicionalismo/ o academismo de M.B." e a "sexualidade bastante indiscreta” em alguns dos versos dele. Em relação ao primeiro tipo de abordagem, "Manuel clássico", trata-se de detectar nessa poesia o "equilíbrio de sentimento e expressão", como se lê no plano diretor da obra; ou ainda, importa reparar o "equilíbrio aticista de forma e expressão", de acordo com uma das notas de trabalho. O segundo terreno exploratório vê a qualidade da "condensação" na lírica bandeiriana, tanto no plano formal, quanto imagético; experiência poética com alto poder simbólico, capaz de fazer "explod[ir] em nós um formidável estado de lirismo, propício a todas as catarses, a todas as transferências, a todas as autopunições.”

Ao se aprofundarem na poesia de Drummond, as notas prévias indiciam os parâmetros críticos de Mário, entre os quais “o valor, a

36 ANDRADE, Mário de. Aspectos da literatura brasileira. op. cit., p. 117. 
valorização do real”, a "obsessão da morte", "a solidão de Carlos”, a "poesia política”. Importava, igualmente, compará-lo com Manuel Bandeira, no que concerne à "natureza' do artista”, assim como compor um paralelo entre as expressões em prosa dos três poetas. Nesse quesito, para Mário, a narrativa de Drummond "é sempre funcionalmente e intrinsecamente poesia. A intuição reina, o desprestígio da lógica é completo. Poesia em prosa."

Em face dessa massa documental heterogênea, norteado por dois planos sumários presentes no dossiê, reconhecendo o método de trabalho de Mário de Andrade, lançando mão das raízes do pensamento crítico dele e municiado pelas percepções teórico-metodológicas da crítica textual e genética, o pesquisador buscará os nexos viáveis entre as peças do conjunto, determinando uma ordem consistente entre outras, concebendo uma obra entre outras possíveis. É, afinal, uma dessas obras que pretendo reconstituir oportunamente, aceitando o desafio de escalar o morro que leva ao imponente Pico dos Três Irmãos.

\section{Sobre o autor:}

\section{Marcos Antonio de Moraes}

Professor Doutor do Instituto de Estudos Brasileiros (IEB-USP). Possui graduação em Letras (Linguística, Português e Francês) e é Mestre e Doutor em Literatura Brasileira em Literatura Brasileira pela USP. Bolsista de Produtividade em Pesquisa do CNPq - Nível 2.

E-mail: moraesusp@gmail.com 